\title{
Effect of excising Freund's adjuvant granuloma on subsequent development of experimental allergic arthritis
}

\author{
D. HIRSCHOWITZ, A. FOX, AND L. E. GLYNN \\ From the MRC Rheumatism Unit, Canadian Red Cross Memorial Hospital, Taplow, Maidenhead, Berks.
}

SUMMARY Rabbits were immunized with antigen in Freund's complete adjuvant. Several weeks later the granuloma which developed was excised one day before joint challenge with antigen. The subsequent development of experimental allergic arthritis (EAA) was not affected, which argues against the chronicity of the disease being maintained by continuous recruitment of mycobacterial debris to EAA joints.

The injection of a soluble, protein antigen into the joints of rabbits previously immunized with that antigen in Freund's complete adjuvant (FCA) results in chronic persisting arthritis-experimental allergic arthritis (EAA) which histologically resembles rheumatoid arthritis (Dumonde and Glynn, 1962; Consden et al., 1971). One explanation for the chronicity of the disease is the possibility that there is a continuous recruitment of macrophages carrying mycobacterial debris, from the FCA granuloma (which develops at the immunization site) to EAA joints. Here it might be released where it could cause tissue damage in its own right or encourage autoimmunization, in either event resulting in further attraction of macrophages.

We present evidence that surgical removal of the FCA granuloma one day before joint challenge with antigen does not affect the subsequent development of the disease, which argues against continuous recruitment of mycobacterial debris to EAA joints.

\section{Materials and methods}

Rabbits were of the Old English strain bred in the animal house of the MRC Rheumatism Unit, Taplow. Freund's incomplete adjuvant (FIA) was purchased from Difco Laboratories, East Molesey, Surrey. Freeze dried Mycobacterium tuberculosis heat killed strains C, DT, and PN mixed was supplied by the Central Veterinary Laboratory, Weybridge, Surrey.

Accepted for publication October 3, 1976

Correspondence to Dr. L. E. Glynn
IMMUNIZATION SCHEDULE

Eighteen rabbits were given a subcutaneous injection of an emulsion consisting of equal parts of FCA and saline containing $10 \mathrm{mg}$ ovalbumin (OA) per $\mathrm{ml}$. 4 weeks later 10 of the animals were anaesthetized by intravenous injection of Nembutal, and $1.0 \mathrm{ml}$ of $1 / 10000$ dilution adrenaline diluted in $10.0 \mathrm{ml}$ lignocaine was injected subcutaneously. A single incision was made and all the granuloma visible to the naked eye removed. The site was then closed with interrupted sutures. The following day a solution of $10 \mathrm{mg} \mathrm{OA}$ in $1.0 \mathrm{ml}$ sterile saline was injected into the left knee joint of all 18 rabbits. The left and right joints were measured regularly for 8 weeks (one animal was killed at 10 days owing to excessive chewing at its left joint) when the animals were killed and left and right joints removed for histology. The subcutaneous operation site was also examined for presence of granuloma material.

\section{Results}

Preliminary experiments in which synovectomies were carried out on joints which had established EAA (in some cases with additional granulomectomies) proved to be extremely traumatic, and many of the animals had to be killed as a result of self injury by chewing at the operated joint. This approach was therefore abandoned. Granulomectomies alone proved to be mild and no animals were lost as a result of the operation. Examination of the operation site at autopsy did occasionally show the presence of small pieces of granuloma, but the vast majority were certainly removed. 


\section{JOINT MEASUREMENTS}

All injected joints were extremely swollen at 24 hours, which indicated a strong immune response. However, by the close of the experiment knee swellings had decreased appreciably in both groups (see Fig.), and the mean swelling in the two groups was of similar magnitude.

\section{HISTOLOGY}

Both groups of animals developed EAA as judged by histological examination of joint sections (Table).

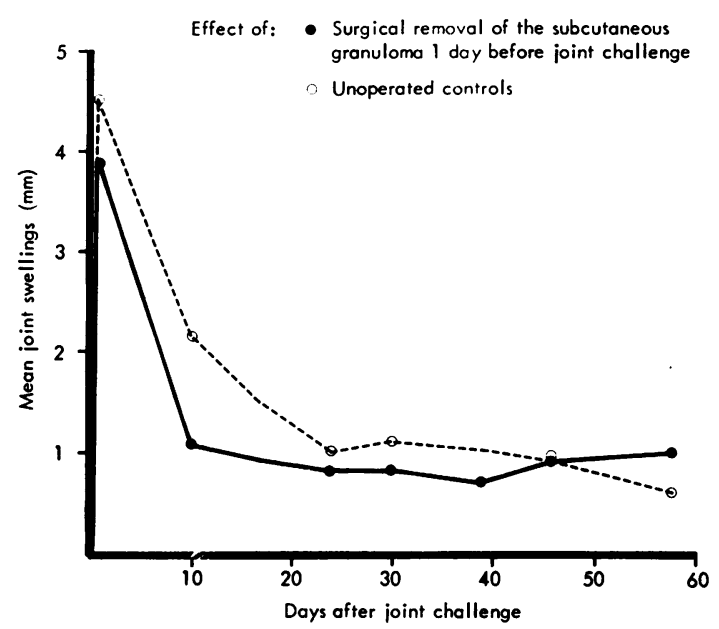

Fig. Mean joint swellings in rabbits after joint challenge. Swelling is expressed as the difference in diameter between the injected (left) and noninjected knees.

Table Degree of arthritis in two groups of rabbits with experimental allergic arthritis. Group I had had the subcutaneous granuloma surgically removed one day before joint challenge with antigen, group II had no surgery

\begin{tabular}{lll}
\hline Grade of arthritis & Group I & Group II \\
\hline $3+$ & 2 & 1 \\
$2+$ & 0 & 2 \\
$1+$ & 4 & 3 \\
\pm & 3 & 1 \\
0 & 1 & 0 \\
\hline
\end{tabular}

\section{Discussion}

Animals developed EAA (as judged by joint swel| $\overrightarrow{\overrightarrow{\hat{\sigma}}}$ ings and histological examination of autops $\bar{x}$ specimens) whether the subcutaneous granulome had been removed one day before intra-articula injection of antigen or not, indicating that continuous recruitment of mycobacteria (from the subcutaneous granuloma) is not an important factor in the pathogenesis of EAA. However, it should be stressed that a small amount of granuloma may not have been removed, and some adjuvant material may have disseminated before surgery. Similar results wer\% obtained on adjuvant arthritis by Ward and Joness (1962) who found that removal of the adjuvant depof more than 2 hours after injection did not affect the subsequent development of allergic arthritis in rats Furthermore we have already provided strong, buf not conclusive, evidence that neither live $M$. aviurn nor [ ${ }^{125}$ I] labelled dead $M$. tuberculosis are carried t joints of animals with EAA from FCA granulom depots (Doble et al., 1975).

We therefore conclude that continuous recruit ment of mycobacterial debris from FCA granuloma depots to EAA joints is not an important factor in the chronicity of EAA.

We thank Mr. J. Watson and department for the histology; Mr. D. Saunders and department for care and attention to the animals; and Mrs. J. Tyler an£ department for the illustration.

\section{References}

Consden, R., Doble, A., Glynn, L. E., and Nind, A. P. (1971 Production of a chronic arthritis with ovalbumin; its retention in the rabbit knee joint. Annals of the Rheumatio Diseases, 30, 307-315.

Doble, A., Fox, A., Glynn, L. E., and Kingston, D. (1975尺̊ The non-passage of mycobacteria from Freund's complete adjuvant granuloma depots to arthritic joints. Britis Journal of Experimental Pathology, 56, 537-543.

Dumonde, D., and Glynn, L. E. (1962). The production arthritis in rabbits by an immunological reaction to fibrin. British Journal of Experimental Pathology, 43, 373-383. $N$

Ward, J. R., and Jones, R. S. (1962). Studies on adjuvantr induced polyarthritis in rats. 1. Adjuvant composition route of injection, and removal of depot site. Arthritis an\$ Rheumatism, 5, 557-564. 